International Journal of Engineering \& Technology, $7(4.5)(2018) 405-409$
International Journal of Engineering \& Technology
SPC
Website: www.sciencepubco.com/index.php/IJET
Research paper

\title{
Performance and Emission Characteristics of a Four Stroke Spark Ignition Engine with Recirculation of Hot and Cold Exhaust Gases
}

\author{
Aritra Ganguly*, Baidya Nath Murmu, Somnath Chakrabarti \\ Department of Mechanical Engineering, Indian Institute of Engineering Science and Technology, Shibpur, Howrah - 711103, \\ West Bengal, India \\ *Corresponding author E-mail: aritra@mech.iiests.ac.in
}

\begin{abstract}
An experiment has been conducted on a four-stroke, four-cylinder spark ignition engine with and without recirculation of exhaust gas for different loads at a constant speed. Two cases were considered, the first in which $10 \%$ and later $20 \%$ of the exhaust gas was directly supplied to the intake manifold at a temperature of $820^{\circ} \mathrm{C}$, while in the second case the same proportions of exhaust gas were cooled in a heat-exchanger to a temperature of $210^{\circ} \mathrm{C}$ before supply. Engine performance parameters like brake specific fuel consumption, brake thermal efficiency were evaluated under those conditions and compared with the same engine operating without recirculation. The corresponding emission characteristics of the engine were also measured using an exhaust gas analyzer which measured the amount of $\mathrm{NO}_{\mathrm{x}}$, $\mathrm{CO}, \mathrm{CO}_{2}$ and un-burnt $\mathrm{HC}$. The performance and emissions characteristics of the engine obtained with hot and cold EGR were compared with reference to the same engine operating without EGR. The study revealed that the performance of the engine was better in terms of brake thermal efficiency and brake specific fuel consumption with cold EGR compared to hot EGR. However, the emissions of CO and HC were higher with cold EGR compared to that of hot EGR.
\end{abstract}

Keywords: Brake fuel consumption; brake thermal efficiency; emission characteristics; exhaust gas recirculation; spark ignition engine

\section{Introduction}

Gasoline engines are widely used in passenger cars, motorcycles and small engines due to their high speed and light weight. The vehicle population is increasing worldwide day by day and this increase is faster in the developing countries of the world like India. The sale of the passenger cars in India have increased from $1,549,882$ in $2007-2008$ to $2,686,429$ in the year 2012-2013 [1]. This significant increase in the vehicle population has increased the emissions of various gases which has aggravated the problem of air pollution. Major constituents of gasoline engine exhaust are oxides of nitrogen $\left(\mathrm{NO}_{\mathrm{x}}\right)$, carbon dioxide $\left(\mathrm{CO}_{2}\right)$, carbon monoxide (CO), unburned hydrocarbon (HC) and particulate matter (PM). The gases coming from the vehicle exhaust have significant effects on the human health. Thus, reducing the emissions of pollutants in conjunction with optimization of performance, comfort and safety is of paramount importance in the development of new engines. Many researchers have worked on the performance of internal combustion engines with Exhaust Gas Recirculation (EGR), but majority of them worked on compression ignition engines. There are only few works available in literature [2-9], which discuss the performance analysis of a spark ignition engine with EGR. Also, no work is available at least in open literature to the authors' knowledge that describes the comparative performance and emission characteristics of a conventional spark ignition engine with hot and cold EGR The aim of the present work is thus to analyze the influence of exhaust gas recirculation on the performance and emission characteristics of a SI engine with different percentages of hot and cold EGR for different loads. The performance and emissions characteristics of the engine obtained with hot and cold EGR have been compared with reference to the same engine operating without EGR. The percentage of exhaust gas recirculation (EGR \%) is a very important parameter which influences the engine performance and can be defined as the percentage of re-circulated exhaust gas to the total intake mixture.

\section{Nomenclature}

\begin{tabular}{|c|c|}
\hline EGR & Exhaust Gas Recirculation \\
\hline bsfc & brake specific fuel consumption \\
\hline SI & Spark Ignition Engine \\
\hline
\end{tabular}

\section{Experimental Details}

The experiments have been conducted on a four cylinder four stroke, water cooled spark ignition engine. The details of the experimental set up are shown in Fig. 1, while the engine specifications are given in Table 1 . The engine is directly coupled to a hydraulic dynamometer of maximum capacity $222.39 \mathrm{~N}$. The water pressure in the hydraulic dynamometer is maintained at a constant value of $1 \mathrm{~kg} / \mathrm{cm} 2$. The brake power of the engine is measured using the hydraulic dynamometer for different engine loads. The experiments have been conducted with a constant engine speed of 1250 RPM under variable load. The speed of the engine has been measured directly using a mechanical tachometer coupled to the engine. As shown in the figure, a control valve (called EGR valve) is provided in the line of exhaust gas to regulate the amount of exhaust gas re-circulated into the intake manifold. To obtain cold 
EGR, a heat exchanger is installed in the EGR line to cool the exhaust gas using water before supplying the same to the intake manifold. The amount of water circulated in the heat exchanger may be regulated using a gate valve. In the experimental setup two known diameter orifices have been installed to measure the ambient air flow consumption and the re-circulated exhaust gas flow. Each orifice is connected to a U-tube manometer which can give the pressure differences for different flow rates. From the pressure difference, the flow rate can be estimated. The amount of fuel consumed in a given time can be found by monitoring the drop in the level of fuel in the fuel tank and recording the time using a stop watch. The temperature of the exhaust gas coming out of the heat exchanger (EGR cooler) has been measured directly using a thermometer. The temperature of the exhaust gas has been measured using a K-type thermocouple installed in the exhaust gas line. For analysis of the exhaust gas, Indus make gas analyzer has been used whose specifications are provided in Table 2.

The exhaust gas analyzer measures the amount of carbon monoxide $(\mathrm{CO})$, carbon dioxide $\left(\mathrm{CO}_{2}\right)$, oxides of nitrogen $\left(\mathrm{NO}_{\mathrm{x}}\right)$ and unburnt hydrocarbon (HC). The amount of $\mathrm{CO}$ and $\mathrm{CO}_{2}$ are measured as percentage volume, while $\mathrm{NO}_{\mathrm{x}}$ and $\mathrm{HC}$ are measured in terms of parts per million ( $\mathrm{ppm})$. The data has been collected after achieving the steady state condition. For each set of experimental data, three sets of readings were collected, the best or the average of the three readings were considered for the final calculation. The experiments were conducted under three conditions which are as follows:

- Engine operation without recirculation of exhaust gas.

- Engine operation with recirculation of hot EGR (10\% and $20 \%$ ) at a temperature of $820^{\circ} \mathrm{C}$.

- Engine operation with recirculation of cold EGR (10\% and $20 \%$ ), the temperature of the gas before recirculation to the intake manifold was reduced to $210^{\circ} \mathrm{C}$ using a water cooled heat exchanger.

Table 1: Specification of the engine

\begin{tabular}{|c|c|}
\hline $\begin{array}{c}\text { Name of the } \\
\text { engine }\end{array}$ & FIAT \\
\hline $\begin{array}{c}\text { No. of cyl- } \\
\text { inder }\end{array}$ & 4 \\
\hline No. of stroke & 4 \\
\hline $\begin{array}{c}\text { Total dis- } \\
\text { placement } \\
\text { volume }\end{array}$ & $1089 \mathrm{cc}$ \\
\hline $\begin{array}{c}\text { Maximum } \\
\text { power }\end{array}$ & $43 \mathrm{HP} @ 5400 \mathrm{rpm}$ \\
\hline $\begin{array}{c}\text { Maximum } \\
\text { torque }\end{array}$ & $71 \mathrm{Nm}$ \\
\hline Bore & $68.02 \mathrm{~mm}$. \\
\hline Stroke \\
\hline $\begin{array}{c}\text { Compression } \\
\text { ratio }\end{array}$ & $74.93 \mathrm{~mm}$. \\
\hline $\begin{array}{c}\text { Cooling } \\
\text { Type }\end{array}$ & $8: 1$ \\
\hline $\begin{array}{c}\text { Method of } \\
\text { loading }\end{array}$ & Water cooled \\
\hline
\end{tabular}

Table 2: Specification of the gas analyser

\begin{tabular}{|c|c|c|}
\hline Sl. No. & Item & Specifications \\
\hline 1. & Gases Measured & $\begin{array}{c}\text { Carbon dioxide, Carbon mon- } \\
\text { oxide Hydrocarbon and Nitric } \\
\text { oxide, oxygen }\end{array}$ \\
\hline 2. & Principle & $\begin{array}{c}\text { Non-Dispersive Infrared for } \\
\text { CO, CO2 and electrochemical } \\
\text { sensor for O2 and NO. }\end{array}$ \\
\hline 3. & Range & $\begin{array}{c}\text { CO: } 0-15.0 \%, \mathrm{CO} 2: 0-20.00 \%, \\
\text { O2: } 0-25.00 \%, \mathrm{NOx}: 0-5000 \\
\text { ppm, HC:0-30000 ppm,0- } \\
5000 \mathrm{ppm}\end{array}$ \\
\hline 4. & Data Resolution & $\begin{array}{c}\mathrm{CO}, \mathrm{CO} 2 \text { and O2:0.01\%, HC, } \\
\text { NO: } 1 \mathrm{ppm}\end{array}$ \\
\hline 5. & Accuracy & $\mathrm{CO}: \pm 0.06 \%$ Vol, CO2: \\
\hline
\end{tabular}



1. Engine; 2. K-type Thermocouple; 3. Gate valve; 4. Exhaust gas analyzer; 5. EGR valve; 6 . EGR cooler; 7. U tube manometer; 8. Orifice; 9. Thermometer; 10. Mixing Chamber; 11. Thermometer; 12. U tube manometer; 13. Orifice; 14. Air filter; 15. Carburetor

Fig. 1: Schematic layout of the experimental set up

\section{Results and Discussions}

In this section the results obtained from the trial on a four stroke spark ignition engine with different percentages of recirculation of exhaust gas has been discussed in terms of engine performance and emission characteristics.

Figure 2 shows the variation of brake thermal efficiency with brake power for a given engine speed for different percentages of hot and cold EGR. It is found that the performance of the engine in terms of brake thermal efficiency reduces when certain fraction of exhaust gas is re-circulated. This reduction is more prominent with increase in the engine load (brake power). From Fig. 2, it is evident that there is a significant reduction in brake thermal efficiency (about $24 \%$ ) at a brake power of $4 \mathrm{~kW}$ when $10 \%$ of the hot exhaust gas is directly re-circulated in the intake manifold at a temperature of $820^{\circ} \mathrm{C}$. However, under the same conditions of brake power, the reduction in brake thermal efficiency is only about $3.6 \%$ (compared to that without recirculation) when the exhaust gas is cooled in a heat exchanger to a temperature of $210^{\circ} \mathrm{C}$ before recirculation. To study the effect of the proportion of exhaust gas recirculation on the performance of the same engine, the percentage of recirculation of exhaust gas was increased to $20 \%$. It is found that the brake thermal efficiency reduced for both hot and cold EGR when the proportion of gas recirculation was increased to $20 \%$. For the brake power of $4 \mathrm{~kW}$, the brake thermal efficiency with $20 \%$ hot EGR is observed to be about $11.5 \%$, while with same proportion of cold EGR, the efficiency value is about $15.9 \%$. The decrease in brake thermal efficiency with EGR (compared to that without recirculation) may be attributed to erratic combustion owing to the dilution of the fuel-air mixture with the exhaust gases. The higher flow rates of EGR reduce the concentration of oxygen in the fresh charge which results in the further reduction in brake thermal efficiency under all conditions of load (brake power). However, with cold EGR the intake charge mixture temperature being lower; the volumetric efficiency is higher than that of hot EGR. So the power developed is more in case of cold EGR which leads to better thermal efficiency compared to that of hot EGR. With cold EGR, the peak engine temperatures during the combustion are also lower and 
thus the heat rejection to the engine coolant gets reduced. So, more amount of heat is available for power generation which leads to better thermal efficiency compared to that of hot EGR.

Figure 3 shows the variation of brake specific fuel consumption (bsfc) with brake power for a given engine speed for different percentages of hot as well as cold EGR. It is found that the bsfc increases when it is operated with recirculation of exhaust gas compared to that without recirculation. It is also noted that there is a significant increase in brake specific fuel consumption (about $35 \%$ ) at a brake power of $4 \mathrm{~kW}$, when $10 \%$ the hot exhaust gas is directly re-circulated in the intake manifold at a temperature of $820^{\circ} \mathrm{C}$ (compared to that with $0 \% \mathrm{EGR}$ ). However, under the same conditions of brake power, the increase in brake specific fuel consumption is only about $3.8 \%$, when the exhaust gas is cooled in a heat exchanger to a temperature of $210^{\circ} \mathrm{C}$ before re-circulation. When the percentage of recirculation of exhaust gas was increased to $20 \%$, the brake specific fuel consumption (bsfc) increased for both hot and cold EGR (compared to that without EGR). At a brake power of $4 \mathrm{~kW}$, the bsfc with $20 \%$ hot EGR is about 0.71 $\mathrm{kg} / \mathrm{kWh}$, while with $20 \%$ cold EGR the same is about 0.52 $\mathrm{kg} / \mathrm{kWh}$ indicating that the performance engine in terms of bsfc is better with cold EGR than that of hot EGR. The increase in bsfc with EGR (compared to that without EGR) is due to the erratic combustion owing to the dilution of the fuel-air mixture with the exhaust gases. However, with cold EGR, the intake charge mixture temperature being lower, the volumetric efficiency is higher than that of hot EGR. So power developed is more in case of cold EGR which leads to a reduction in brake specific fuel consumption.

Figure 4 shows the variation of emission of $\mathrm{CO}$ with brake power for a given engine speed for different percentages of hot and cold EGR. It is observed that the emission of $\mathrm{CO}$ increases with increase in brake power for all the cases. However, it is found that the emission of $\mathrm{CO}$ is higher when the engine is operated with recirculation of exhaust gas. It may be noted that there is a marginal increase in $\mathrm{CO}$ emission (about 2.7\%) at a brake power of $4 \mathrm{~kW}$, when $10 \%$ of the hot exhaust gas is directly re-circulated in the intake manifold at a temperature of $820^{\circ} \mathrm{C}$. However, under the same conditions of brake power, the increase in $\mathrm{CO}$ emission is significantly higher (about 9\%), compared to that without EGR when the exhaust gas is cooled before recirculation. When the percentage of recirculation of exhaust gas was increased to $20 \%$ the $\mathrm{CO}$ emission increased for both hot and cold EGR. It is observed that for a brake power of $4 \mathrm{~kW}$, the CO emission with $20 \%$ hot EGR was about $6 \%$, while with same proportion of cold EGR, it was marginally higher about $6.5 \%$ by volume compared to that without EGR. The increase in CO emission with EGR is due to the fact that the recirculated exhaust gas replaces some of the oxygen present in the fresh charge which decreases the rate of reactions and promotes incomplete combustion. However, the emission of $\mathrm{CO}$ is higher when the exhaust gas is cooled before recirculation for all loads compared to that of hot EGR possibly due to the fact that with cold EGR the peak cylinder temperatures are lower which in turn further reduces the rate of chemical reactions and increases the probability of incomplete combustion.

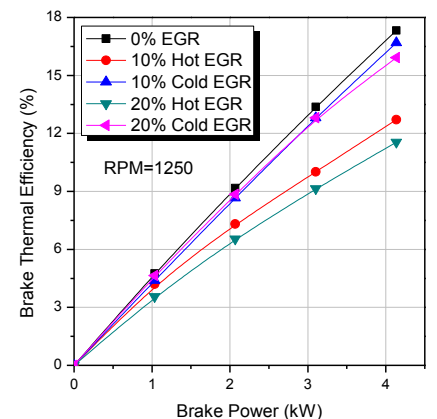

Fig. 2: Variation of brake thermal efficiency with brake power for different percentage of hot and cold EGR



Fig. 3: Variation of bsfc with brake power for different percentage of hot and cold EGR



Fig. 4: Variation of CO with brake power for different percentage of hot and cold EGR

Figure 5 shows the variation of $\mathrm{HC}$ emission with brake power for a given engine speed for different percentages of hot and cold EGR. It is observed that the HC emission increases with increase in brake power and with recirculation of exhaust gas. From Fig. 5, it is evident that there is a marginal increase in $\mathrm{HC}$ emission (about $3.5 \%$ ) at a brake power of $4 \mathrm{~kW}$ when $10 \%$ the hot exhaust gas is directly re-circulated in the intake manifold. However, under the same conditions of brake power, the increase in HC emission is significantly higher (about 14\%), compared to that without EGR when the exhaust gas is cooled in a heat exchanger before recirculation. When the percentage of recirculation of exhaust gas was increased from 10 to $20 \%$, the $\mathrm{HC}$ emission increased for both hot and cold EGR. The increase in the concentration of $\mathrm{HC}$ with increase in the rate of EGR is due to the reduction of the availability of oxygen in the inlet charge by the re-circulated exhaust gases in the cylinder. The lack of availability of oxygen in the intake charge is responsible for incomplete combustion and higher emissions of HC. The emission of HC is also associated with the fraction of charge trapped in the crevice volumes in the combustion chamber, quenching near the wall and undergoing partial combustion. In an engine with high levels of EGR, lower temperatures coupled with decreased reactivity results in larger quench distances, leaving more unburned fuel in the region near the wall. The effect of lower in-cylinder temperatures is more prominent with cold EGR due to which the HC emission is higher. Figure 6 shows the variation of oxides of nitrogen emission with brake power for a given engine speed for different percentages of hot and cold EGR. It is observed that the $\mathrm{NO}_{\mathrm{x}}$ emission increases with the increase in brake power.

However, it is found that the emission of $\mathrm{NO}_{\mathrm{x}}$ reduces when it is operated with recirculation of exhaust gas. As observed, the $\mathrm{NO}_{x}$ emission was about $370 \mathrm{ppm}$ at a brake power of $4 \mathrm{~kW}$ when $10 \%$ of the hot exhaust gas was recirculated in the intake manifold at a temperature of $820^{\circ} \mathrm{C}$. However, under the same conditions of brake power, the reduction in $\mathrm{NO}_{\mathrm{x}}$ emission was more significant (about $340 \mathrm{ppm}$ ), when same proportion of the gas is cooled in a heat exchanger to a temperature of $210^{\circ} \mathrm{C}$ before re-circulation. It 
may be noted that when the percentage of recirculation of exhaust gas was increased to $20 \%$, the concentration of $\mathrm{NO}_{\mathrm{x}}$ further reduced for both hot and cold EGR compared to that without EGR. The formation of $\mathrm{NO}_{\mathrm{x}}$ is highly dependent on the in-cylinder temperature, oxygen concentration and the residence time of the charge for the reactions to take place. Higher the temperature, higher is the tendency for $\mathrm{NO}_{\mathrm{x}}$ formation. The $\mathrm{NO}_{\mathrm{x}}$ emissions reduce with recirculation of exhaust gas, due to the lowering of the peak combustion temperatures. In case of cold EGR, $\mathrm{NO}_{\mathrm{x}}$ emission is expected to be lower than that with hot EGR due to lower gas temperature.

Figure 7 shows the variation of $\mathrm{CO}_{2}$ emission with brake power for a given engine speed for different percentages of EGR. It is found that the emission of $\mathrm{CO}_{2}$ increases with the increase in brake power. However, it is found that the emission of $\mathrm{CO}_{2}$ reduces when it is operated with recirculation of exhaust gas. It is found that there is a reduction in $\mathrm{CO}_{2}$ emission (about 5.5\%), at a brake power of $4 \mathrm{~kW}$, when $10 \%$ of the exhaust gas is recirculated in the intake manifold at a temperature of $820^{\circ} \mathrm{C}$. However, under the same conditions of brake power, the reduction in $\mathrm{CO}_{2}$ emission is significant, (about 16\%) compared to that without EGR when the exhaust gas is cooled in a heat exchanger before recirculation. When the percentage of gas recirculation was increased to $20 \%$, the concentration of $\mathrm{CO}_{2}$ emission reduced to $8.9 \%$, while with same proportion of cold EGR, the $\mathrm{CO}_{2}$ emission was about $8 \%$ by volume. The $\mathrm{CO}_{2}$ emission reduced with increase in percentage of EGR, possibly due to the decrease in oxygen concentration in the gaseous fuel-air mixture. With cold EGR, the rate of oxidation of fuel in the combustion chamber gets further reduced due to lower cylinder temperature, resulting in less emission of $\mathrm{CO}_{2}$.

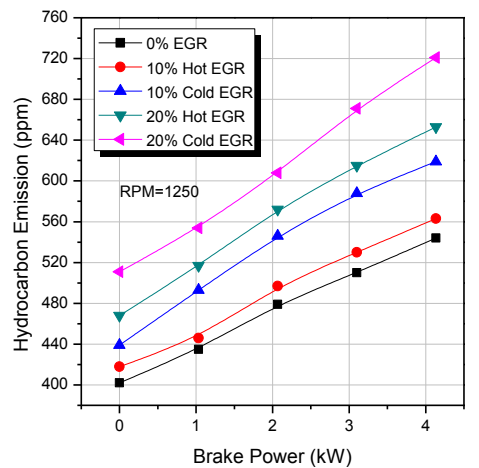

Fig. 5: Variation of $\mathrm{HC}$ with brake power for different percentage of hot and cold EGR

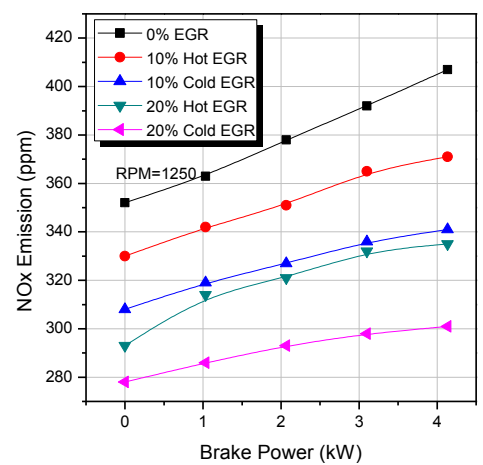

Fig. 6: Variation of $\mathrm{NO}_{\mathrm{x}}$ with brake power for different percentage of hot and cold EGR

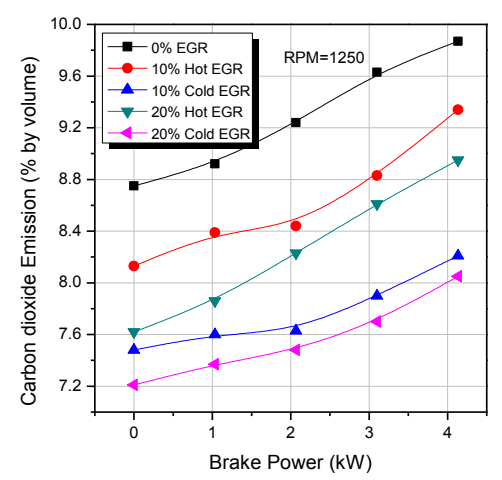

Fig. 7: Variation of $\mathrm{CO}_{2}$ with brake power for different percentage of hot and cold EGR

\section{Conclusion}

In this work, an experiment has been conducted on a four stroke, four cylinder SI with and without recirculation of hot and exhaust gas for different loads. Following are the major conclusions that can be drawn from the work:

a) The brake thermal efficiency of the engine is found to reduce when the exhaust gas was recirculated back to the intake manifold. However, the brake thermal efficiency is better when the exhaust gas was cooled before recirculation compared to that of the direct recirculation of the hot gas.

b) The bsfc is found to increase with increase in percentage of EGR. However, the bsfe is better when the exhaust gas was cooled before recirculation compared to that direct recirculation of the hot exhaust gas.

c) The NOx emission reduced when the exhaust gas was recirculated back to the intake manifold. However, the NOx emission is further reduced when the exhaust gas was cooled before recirculation.

d) The HC emission increased when the exhaust gas was recirculated back to the intake manifold compared to that engine operating without EGR. The emission of HC further increased when the exhaust gas was cooled before recirculation compared to that direct recirculation of the hot exhaust gas at a temperature of $820^{\circ} \mathrm{C}$.

e) The emission of $\mathrm{CO}$ concentration is found to be higher when the exhaust gas was re-circulated back to the intake manifold compared to the same engine operating without EGR. However, the emission of $\mathrm{CO}$ concentration is further augmented when the exhaust gas was cooled before recirculation.

f) The emission of $\mathrm{CO} 2$ concentration decreased when the exhaust gas was recirculated back to the intake manifold compared to that engine operating without EGR. However, the $\mathrm{CO} 2$ concentration further decreased when the exhaust gas was cooled before recirculation compared to that direct recirculation of the hot gas.

\section{References}

[1] Society of Indian Automobile Manufacturers (SIAM), 2014, Industry Statistics, Domestic Sales Trend, Available online at 118.67.250.203//scripts/domestic-sales-trend.aspx. (Accessed on 28th October 2014).

[2] Shojaeefard MH, Tahani M, Etghani MM \& Akbari M (2013), Cooled EGR for a Turbo Charged SI Engine to Reduce Knocking and Fuel Consumption. International Journal of Automotive Engineering 3 (3), 474-481.

[3] Ponnusamy P, Subramanian R \& Nedunchezhian N (2012), An experimental study on the effect of EGR on performance and emission on four stroke SI engine with various catalytic coatings. Elixir Thermal Engineering 43, 6586-6589.

[4] Su J, Xu M, Li T, Gao Y \& Wang J (2014), Combined effects of cooled EGR and a higher geometric compression ratio on thermal 
efficiency improvement of a downsized boosted spark-ignition direct-injection engine.Energy Conversion and Management 78, 6573.

[5] Li T, Wu D \& Xu M (2013), Thermodynamic analysis of EGR effects on the first and second law efficiencies of a boosted sparkignited direct-injection gasoline engine. Energy Conversion and Management 70, 130-138.

[6] Cha J, Kwon J, Cho Y \& Park S (2001), The Effect of Exhaust Gas Recirculation (EGR) on Combustion Stability, Engine Performance and Exhaust Emissions in a Gasoline Engine. KSME International Journal 15, 1442 -1450.

[7] Wei H, Zhu T, Shu G, Tan L \& Wang Y (2012), Gasoline engine exhaust gas recirculation - A review. Applied Energy 99, 534-544.

[8] Alger T, Gingrich J, Roberts C \& Mangold B (2011), Cooled exhaust-gas recirculation for fuel economy and emissions improvement in gasoline engines. International Journal of Engine Research 12, 252-264.

[9] Wei L, Ying W, Longbao Z \& Ling S (2007), Study on improvement of fuel economy and reduction in emissions for stoichiometric gasoline engines. Applied Thermal Engineering 27, 2919-2923. 